\title{
Theranosties
}

Editorial

2012; 2(1):1-2

\section{One Year after a Successiul Start of Theranostics}

\section{Xiaoyuan (Shawn) Chen $\bowtie$}

Laboratory of Molecular Imaging and Nanomedicine, National Institute of Biomedical Imaging and Bioengineering, National Institutes of Health, Maryland 20892, USA

$\bowtie$ Corresponding author: Shawn.Chen@nih.gov

(C) Ivyspring International Publisher. This is an open-access article distributed under the terms of the Creative Commons License (http://creativecommons.org/ licenses/by-nc-nd/3.0/). Reproduction is permitted for personal, noncommercial use, provided that the article is in whole, unmodified, and properly cited.

Published: 2012.01 .01

\begin{abstract}
As Theranostics begins its second year of publication, I would like to thank our authors, reviewers, and audience for their outstanding support in $20 \mathrm{I}$ I. I look forward to working with you in 2012 to continue our mission to distinguish Theranostics as a leader of publishing cutting edge research in this important and emerging field.
\end{abstract}

Key words: Theranostics, journal.

"Happy New Year" from Theranostics, and welcome to the first issue of 2012! Theranostics was launched at the beginning of 2011, with the intention of providing a forum for sharing high quality research results and for discourse in the fields of in vitro diagnostics and prognostics, in vivo molecular imaging, molecular therapeutics, image-guided therapy, biosensors, systems biology, translational and personalized medicine, and a broad spectrum of biomedical research applicable to the future of theranostics. This has been a very successful first year. We have taken all the important steps toward becoming a truly interdisciplinary, rigorous, and rapid publication. Several features of Theranostics have been viewed very positively by the authors and readers.

- Open Access: Theranostics publishes papers using a Gratis Open Access model in which accepted papers are freely and immediately available on the journal's website. It is our belief that the Open Access model will become a major force in scientific publishing in the near future, and we hope that Theranostics will be a leading journal in this new movement.

- Prestigious Editorial Board: One of the key support structures of Theranostics is its Editorial Board.
We have brought together a vibrant group of eminent scientists from very diversified backgrounds and geographical regions to join the board;

- Table of Contents Graphics: Graphics in the table of contents help draw attention to the content of particular journal articles. These graphics attempt to give readers quick visual indications of important elements of papers. The graphics can be structures, schemes, graphs, formulas, pictures, or pictorial concepts, but not tables or text.

- High Impact and Citation: A total of 34 items (31 articles, 2 editorials and 1 commentary) have been published in the first year, and total citations in 2011 have exceeded 120. Not only have the Theranostics papers been widely cited, but the Journal itself has been widely cited at conferences and in the scientific literature;

- Strong Web and Database Presence: Manuscripts accepted for publication in Theranostics immediately reach a worldwide scientific audience on the web via the Ivyspring International Publisher. The published papers are highly visible in search engines. Full texts of articles are included in PubMed Central, PMC Canada, and UK PMC. 
Abstracts are included in PubMed. We are very delighted that the journal has been accepted into Science Citation Index (SCI/SCIe) within first year of publication!

- Rapid Publication Process: All papers are rapidly screened for suitability. Papers that are sent out for review are assessed within a few weeks. Galley proofs are typically provided to the authors within two weeks after final version of the manuscript is received, and papers are posted on-line within a few days of final galley correction.

This success would have been impossible without the help of many. First, I would like to thank the many authors and reviewers of papers - you have joined together and formed a dynamic and vital community. I also would like to take this opportunity to thank the truly capable team of dedicated professionals in the Ivyspring Publisher who have made the publication process such a prompt and smooth one.

There will be some new developments in the Journal in the new year:

- Monthly Issues: Due to the ever increasing number of submissions, we will be moving to monthly issues with cover art. If you have a stunning image to accompany your paper, please call our attention to it, and we will consider it for possible cover art.

- Themed Issues: Continuing on the topic of building great content, high-profile themed issues will be regular occurrences for Theranostics. These will focus on emerging and rapidly developing fields of theranostics, have Guest Editors who are experts in their field, give up-to-date overviews, and provide platforms for the presentation and discussion of new research. Our first themed issue this year will be on Magnetic $\mathrm{Na}$ noparticle-Based Theranostics, Guest Edited by Prof. Jin Xie of the University of Georgia and Prof. Sangyong Jon of the Gwangju Institute of Science and Technology. To find out more about how you can engage in special issues, please refer to our website: http://www.thno.org/ specialissue.

- Author Biography: Authors now have the option to publish a biography to accompany their papers, with information about their training, past and present positions, research interests, awards, etc. This will increase the profiles of the authors and be well received by international readers. Author biographies can be added to the ends of papers, in a section called "Author Biography".
Thank you again to the authors, reviewers, and audience for your outstanding support in 2011. I look forward to working with you in 2012 to continue our mission to distinguish Theranostics as a leader in the publication of cutting edge research in molecular diagnostics, imaging and therapy. 